\title{
La escritura testimonial en Rodolfo Walsh: politización del arte y experiencia histórica
}

\section{Non-fiction literature in Rodolfo Walsh: politicization of art and historical experience}

\author{
Fabiana Grasselli \\ Grupo de trabajo «Sociedad, Política y Género», INCIHUSA-CONICET \\ fhebeg@hotmail.com \\ Mariano Salomone \\ Grupo de trabajo «Sociedad, Política y Género», INCIHUSA-CONICET \\ marianosalomone@hotmail.com
}

Resumen - La obra de Rodolfo Walsh está marcada por una fuerte vinculación entre práctica estética y práctica política. En el presente trabajo proponemos abordar la constelación de textos «testimoniales» del escritor, correspondientes a las décadas de los sesenta y setenta. Estos escritos movilizan una concepción del arte como portador de cierta "peligrosidad», que está anclada a su enorme potencialidad para constituir una intervención sobre la realidad histórico-social. Nos ocupamos de analizar el modo en que se relacionan, en dicha constelación de textos, la crítica a la sacralización del arte burgués, las estrategias de escritura (el montaje) y la voluntad de contribuir a la reconstrucción de una memoria social que dé cuenta de la experiencia histórica de los sectores populares (su estado de emergencia, la violencia política).

Palabras clave: Rodolfo Walsh, géneros testimoniales, politización del arte, experiencia histórica.

Abstract - The works of Rodolfo Walsh are marked by a strong connection between an aesthetic and a political practice. In this work we propose to engage in the constellation of nonfiction texts written by the author in the $60 \mathrm{~s}$ and $70 \mathrm{~s}$ period. These texts pursue a conception of art as bearer of a certain "danger» that is anchored to its enormous power to embody an intervention in historical and social reality. We analyze the way in which certain elements relate to each other: the criticism of a sacralization of bourgeois art, the strategies of writing (the montage), and the will to contribute to the reconstruction of a social memory that explains the historical experience of the working classes (their state of emergency, the political violence).

Keywords: Rodolfo Walsh, nonfiction literature, politicization of art, historical experience. 
La historia irrumpirá de manera decisiva en su vida y no podrá permanecer indiferente. La política, entonces, encontrará su más pura expresión en la palabra.

Rodolfo Walsh, reconstrucción de un hombre, documental de Luciano Zito

\section{INTRODUCCIÓN}

La tarea de reconstruir el programa estético-político de Rodolfo Walsh implica analizar sus posicionamientos en torno a algunos tópicos recurrentes en el campo intelectual de los años sesenta y setenta. Dichos posicionamientos presentan la particularidad de proponer una vinculación fuerte entre palabra y acción, entre escritura testimonial y práctica política, entre su actividad artística y la experiencia histórica de los sectores populares: es del proceso de transformación del mundo que el periodismo de Walsh da testimonio. A diferencia de las alternativas seguidas por otros y otras intelectuales del mismo período, Walsh optó por una militancia revolucionaria comprometida con la lucha armada, sin por ello abandonar la actividad artística, aun cuando estuviera atravesada por tensiones. De allí la importancia de determinar ciertos elementos y modulaciones de su programa, en tanto constituyó una importantísima operación hacia el interior de la literatura que intentó, en un momento histórico singular, subvertir sus lógicas y formas institucionalizadas.

En este marco, nuestro trabajo se propone abordar la opción de Walsh por los géneros testimoniales y su vinculación con ciertos problemas relativos a la concepción del arte como portador de una peligrosidad. Desde el punto de vista de la tradición de los sujetos subalternos, de su dialéctica histórica propia, puede decirse que el arte está anclado a una peligrosidad en un doble sentido, ella es tanto aquello que lo produce, su motor, como lo que puede, a la vez, producir. Se trata de una escritura nacida en ese instante de peligro que supone todo momento de radicalización de la lucha de clases; pero al mismo tiempo, al dar testimonio de la violencia política que en ella se inscribe, esa reescritura se vuelve peligrosa, pues arroja un haz de luz sobre el mundo, capaz de astillar la continuidad histórica establecida por las clases dominantes, de constituir una intervención sobre la realidad histórico-social. En el presente artículo, proponemos revisar los modos en que se configura el vínculo entre práctica política, escritura testimonial y construcción de una memoria colectiva de las clases populares en algunos textos de Walsh, en tanto elementos emergentes que dan cuenta de una experiencia histórica que, al mismo tiempo, constituye una crítica a la sacralización del arte burgués y un gesto de politización del arte.

\section{CONFIGURACIONES E IMPLICANCIAS DE LA IDEA DE MEMORIA COLECTIVA}

Existen, en la trayectoria de Rodolfo Walsh, puntos de inflexión en los que el elemento común parece ser la condensación y mutua resignificación de los diferentes ámbitos de las prácticas del escritor. En dichos momentos - la campaña periodística y elaboración 
de Operación Masacre (1957-1958), su primer viaje a Cuba donde funda la Agencia de noticias Prensa Latina (1959), su participación en la CGT de los Argentinos (1968), su ingreso a la organización Montoneros (1973) - los acontecimientos de la esfera de la militancia y las decisiones en el espacio de la escritura y de la vida intelectual se implican e impactan mutuamente, configurando una zona de tensión. Sin duda, lo borroso de los límites entre prácticas políticas y prácticas intelectuales, que se configuró como el signo de la época durante el bloque temporal sesenta/setenta en lo relativo al quehacer de los hombres y mujeres de la cultura, constituye una clave para interpretar aquellos puntos de inflexión.

En este sentido, nos interesa abordar un conjunto de textos producidos entre 1968 y 1977, conformado por «Guevara» (1968), el «Prólogo a Los que luchan y los que lloran de Jorge Ricardo Masetti» (1969), las «cartas polémicas» $»^{1}$ (según las denominaba el propio autor) y una crónica sobre el «Cordobazo» ${ }^{2}$. En ese grupo de escritos, se observa un elemento emergente constituido por lo que podríamos definir como una modulación en su programa estético-político, a partir de la cual se resignifica y se enriquece la opción por los géneros testimoniales cuando, a la denuncia de la violencia hacia los oprimidos y a la articulación de la versión contrahegemónica de los hechos, se le añade una idea de memoria social como práctica contestataria de disputa por el sentido del pasado ${ }^{3}$.

En el caso de «Guevara», el «Prólogo a Los que luchan y los que lloran» y las «cartas», nos enfrentamos a un grupo de textos que poseen una serie de rasgos en común: a) su producción es motivada por la muerte en combate de luchadores y luchadoras que constituían una referencia para Walsh (el Che Guevara, Jorge Masetti, su hija Victoria Walsh, su amigo Francisco Urondo); los compañeros y compañeras desaparecidos del primer año de la dictadura; b) la escritura se propone como un ejercicio de rememoración en el que, o bien se reconstruyen trayectorias de militancias en el marco de las luchas populares emancipatorias en América Latina y Argentina, o bien se denuncian las tergiversaciones y ocultamientos de información por parte de las versiones oficiales acerca de esa trayectoria y también de los procesos económicos, sociales, políticos y culturales; c) los relatos se articulan a partir de testimonios del propio autor y de otros testigos, que completan con información necesaria; d) aparecen alusiones a un concepto de memoria entendida como territorio de conflicto, en el que se enfrentan diversas narrativas sobre los procesos

1 Bajo la denominación «cartas polémicas» ubicamos los textos «Carta a Vicky» (1976), "Carta a mis amigos» (1976) y «Diciembre 29» (1976) [sobre la muerte de Francisco Urondo], recopilados por Daniel Link (Walsh, Ese hombre y otros papeles). También está incluida «Carta abierta de un escritor a la Junta Militar», escrita en marzo de 1977, al cumplirse un año del golpe militar que derrocó a Isabel Perón, y puesta a en circulación «de mano en mano» hasta el 19 abril de 1977, cuando fue publicada en Circular de Contrainformación, $\mathrm{N}^{\circ} 2$, Oficina de Prensa y Difusión del Partido Montonero. Aquí trabajamos con la edición realizada por Baschetti (Rodolfo Walsh, vivo). Tomamos la nomenclatura «cartas polémicas» del texto de Lilia Ferreyra: «Concebía una nueva forma de acción política como una producción totalizadora que abarcaba la denuncia, el testimonio, el análisis político o ideológico, el relato literario. Sus «cartas polémicas — como las llamaba - tenían un objetivo: denunciar no sólo la represión del poder o la política económica, sino todas las otras manifestaciones ideológicas del régimen militar» (195).

2 Texto sin datación precisa, escrito en una fecha posterior al 29 de mayo de 1969.

3 Como utillaje conceptual sobre la noción de memoria utilizamos los aportes de Elizabeth Jelin, Maurice Halbwachs, Paul Ricoeur y Miguel Dalmaroni. Por otra parte, además de esos textos pertenecientes al campo de los estudios sobre la problemática de «la memoria», han sido importantes las conceptualizaciones de otros autores y autoras que, por fuera de dicho campo, permiten articularlo a las determinaciones particulares de la historia de los sectores subalternos: tales como Benjamin (Para una crítica), Gramsci, Löwy, Voloshinov y Catanzaro, por citar algunos. El conjunto de estas conceptualizaciones son usadas a modo de herramientas teóricas para iluminar la interpretación de los textos abordados. 
históricos. Los alcances de dicho concepto abarcan también la idea de construcción del recuerdo para la memoria social y la noción de práctica de resistencia.

Así lo vemos, por ejemplo, en «Guevara»:

El agente de la CIA que según la agencia Reuter codeó y panceó a cien periodistas que en Valle Grande pretendían ver el cadáver, dijo una frase en inglés: «awright, get the hell out of here». Esta frase con su sello, su impronta, su marca criminal, queda propuesta para la historia. Y su necesaria réplica: alguien tarde o temprano se irá al carajo de este continente. No serán los que nacieron en él. No será la memoria del Che. Que ahora está desparramado en cien ciudades entregado al camino de quienes no lo conocieron (285).

También podemos leer en el «Prólogo a Los que luchan y los que lloran»: «Periodista, sabía cómo se construyen renombres y se tejen olvidos. Guerrillero, pudo presumir que si era derrotado el enemigo sería el dueño momentáneo de su historia» (127).

En su «Carta a Vicky» hace referencia a la memoria y al recuerdo: "No podré despedirme de vos, vos sabés por qué. Nosotros morimos perseguidos, en la oscuridad. El verdadero cementerio es la memoria. Ahí te guardo, te acuno, te celebro y quizá te envidio, querida mía» (266).

Del mismo modo lo encontramos en la «Carta abierta de un escritor a la Junta Militar»:

Si una propaganda abrumadora, reflejo deforme de hechos malvados no pretendiera que esa Junta procura la paz, que el general Videla defiende los derechos humanos o que el almirante Massera ama la vida, aún cabría pedir a los señores Comandantes en Jefe de las 3 Armas que meditaran sobre el abismo al que conducen al país tras la ilusión de ganar una guerra que, aun si mataran al último guerrillero, no haría más que empezar bajo nuevas formas, porque las causas que hace más de veinte años mueven la resistencia del pueblo argentino no estarán desaparecidas sino agravadas por el recuerdo del estrago causado y la revelación de las atrocidades cometidas.

Estas son las reflexiones que en el aniversario de su infausto gobierno he querido hacer llegar a los miembros de esa Junta, sin esperanza de ser escuchado, con la certeza de ser perseguido, pero fiel al compromiso que asumí hace tiempo de dar testimonio en momentos difíciles (253).

Según se desprende de fragmentos anteriores, la problemática de la memoria refiere a un territorio de conflicto ideológico, sobre el cual los sectores dominantes operan para dejar la «impronta» de su interpretación de los hechos históricos. Frente a esta historia, es decir, la historia oficial, la recuperación de una memoria subterránea y alternativa se presenta como una réplica necesaria desde los sectores contrahegemónicos. Resulta necesaria porque, siguiendo una perspectiva benjaminiana, la memoria a la que contribuyen los relatos de Walsh articula recuerdos que se hacen presentes al sujeto en el instante de peligro - «sin esperanzas de ser escuchado, con la certeza de ser perseguido». En tal sentido, hay una conciencia del carácter construido de la memoria: tanto los recuerdos como el olvido «se tejen", se hilan, son el producto de prácticas político-discursivas que expresan el conflicto transitado por los grupos sociales en los procesos históricos de la actualidad; esto es, el pasado rememorado es aquel que adviene y contribuye a configurar la conflictividad del presente. Aquí el conocimiento histórico tiene como punto de partida el reconocimiento del estado de emergencia en el que se encuentran los sectores subalternos, esa peligrosidad impone «límites y presiones» (Williams) a los procesos de rememoración. Así también, el recuerdo colectivo es presentado como alimento y justifi- 
cación de las luchas populares, y vinculado a eso, la noción de testimonio como posibilitador del recuerdo que moviliza.

Dentro de las implicancias ideológicas de estos textos urgentes de Walsh aparece, como planteamos, la idea de que existen diversas narrativas que se van articulando alrededor de un acontecimiento y van conformando las memorias de los diferentes sectores sociales. En el caso de los sectores populares y la militancia revolucionaria, los relatos a partir de los cuales se reconstruye y explica la experiencia histórica ponen de manifiesto el ajuste de cuentas entre el pasado y el presente. Esa relación dialéctica entre pasado y presente aparece como desarrollada a partir de un vínculo solidario entre política y memoria: es la política (los conflictos y acontecimientos político-sociales del presente) la que estructura y hace posibles determinados procesos de rememoración del pasado de manera colectiva; a la vez que es la rememoración del pasado uno de los espacios de donde los sujetos extraen el espíritu y la fortaleza necesaria para legitimar su lucha política y proyectar un futuro deseado. Dicha idea de memoria tiene una dimensión social o colectiva (Halbwachs), entonces, al igual que cualquier otra práctica cultural, posee un carácter político en tanto se configura en la lucha ideológica. Lo que está en juego en cada práctica cultural, y por ende, en el recuerdo del pasado, es que constituye una herramienta en los conflictos por los que atraviesan los grupos sociales y, por tanto, tiene implicancias para el desarrollo de esa pugna constante. Es por ello que para Walsh las memorias contrahegemónicas constituyen también un espacio de resistencia, donde las historias del pueblo, de los y las militantes y combatientes, de los perseguidos y las perseguidas pueden ser guardadas y protegidas de la oscuridad y el ocultamiento, con la intención de configurar la trama de una tradición que anude el pasado y el presente, aun cuando ese lazo implique realizar una lectura a contrapelo de la experiencia histórica.

En el texto "Cordobazo" se configura una noción de memoria social que aparece expresada bajo diversas formulaciones, en el marco de una crónica de lo que posteriormente sería conceptualizado como la apertura del período de «lucha de calles» (Balvé). La importancia de dicho texto radica en el hecho de que resitúa la cuestión de la memoria social en el ámbito de la política (la lucha de calles), evidenciando que el conocimiento de la historia (la crónica) no corresponde al recuento de los acontecimientos «tal cual sucedieron", sino a la visualización de la violencia política de la que son producto: así, una reconstrucción histórica que tiene en cuenta no sólo lo que efectivamente sucedió, sino también aquellos pasados (deseos, expectativas y prácticas) que quedaron truncados, cuestiona la inevitabilidad de este presente (el que heredamos entre todos los posibles) y permite imaginar la posibilidad de otro futuro.

En el "Cordobazo», Walsh reconstruye el relato de los hechos y la experiencia de lucha de los sectores populares, disputando el sentido de diversos procesos y las informaciones oficiales, para denunciar la violencia de la represión ilegal y desentrañar los verdaderos objetivos del gobierno dictatorial:

Es la toma de conciencia contra tantas prohibiciones. Nada de tutelas ni usurpadores del poder, ni de cómplices participacionistas.

El saldo de la batalla de Córdoba, «El Cordobazo», es trágico. Decenas de muertos, cientos de heridos. Pero la dignidad y el coraje de un pueblo florecen y marcan una página histórica argentina y latinoamericana que no se borrará jamás [...]

Nuestras clases dominantes han procurado siempre que los trabajadores no tengan historia, no tengan doctrina, no tengan héroes ni mártires. Cada lucha debe empezar de nuevo, separada de las luchas anteriores. La experiencia colectiva se pierde, las lecciones se olvidan. 
La historia parece así como propiedad privada cuyos dueños son los dueños de todas las cosas. Esta vez es posible que se quiebre el círculo [...].

Si realizamos un análisis de la noción de memoria que suponen los fragmentos anteriores, podemos distinguir varias significaciones: en primer lugar, aparece la alusión al contenido "marcas», en el sentido de huellas, improntas. Las luchas del pueblo dejan una marca en las "páginas de la historia», que no puede ser borrada. Hay una recurrencia en el uso de la metáfora de la marca/impronta para conceptualizar las consecuencias de las prácticas de construcción de las narrativas sobre el pasado. En segundo lugar, como contrapartida, las clases dominantes procuran invisibilizar la historia de los sectores populares, fragmentarla, apropiársela instaurando una versión del relato de los hechos hegemónica y monológica (Bajtin). En otras palabras, los sectores hegemónicos, en la institucionalización de su narrativa histórica, realizan una doble operación de construcción y destrucción: se construye la historia oficial y se destruyen las huellas de las memorias contrahegemónicas; se quiebra así la continuidad de la historia de los oprimidos.

El conjunto de textos testimoniales de Walsh reubica la problemática de la memoria en el terreno de la política y pone de manifiesto su vínculo con el conocimiento histórico. En ellos, el conocimiento de la historia no forma parte de una inquietud teórica, sino, antes bien, de una urgencia vital. Algo que supo reconocer Walter Benjamin al problematizar el concepto de historia: «articular históricamente el pasado no significa conocerlo «como verdaderamente ha sido', sino ‘adueñarse de un recuerdo tal como éste relampaguea en un instante de peligro»" (Para una crítica de la violencia, 108). Así, el conocimiento del pasado sería el acto por el cual se le presenta al sujeto un recuerdo que lo salva. Hay, en la perspectiva benjaminiana, un primado de la política sobre la historia. En tal sentido, Gisela Catanzaro recuerda que lo que se juega en el tablero de ajedrez de la primera de las Tesis de filosofía de la historia no es, en principio, «una guerra entre distintas representaciones de la historia, sino una imagen de la historia como campo de batalla: sólo en la medida en que éste es su campo, interesa en la guerra también la lucha por su (verdadera) representación» (31).

\section{MEMORIA COLECTIVA Y EXPERIENCIA HISTÓRICA EN LA ESCRITURA TESTIMONIAL DE RODOLFO WALSH}

Se puede señalar entonces que la constelación de discursos conformada por "Guevara», el «Prólogo a Los que luchan y los que lloran», "cartas polémicas» y la crónica sobre el "Cordobazo» posee un núcleo de sentido constituido en y por la dialéctica históricosocial entre práctica política, testimonio y memoria social. La temporalidad densa que inauguran esas relaciones - una trama simbólica que compromete pasado, presente y futuro- produce cierta gravitación en la constelación de textos abordada, habilitando una lectura desde la cual la escritura testimonial, en tanto eje del programa estético-político de Rodolfo Walsh, se enriquece y resignifica. Dichos textos dan cuenta de la asunción por parte del escritor de un compromiso histórico y político, a la vez que artístico, que emerge frente a la agudización del conflicto social y el recrudecimiento de la violencia represiva en Argentina y América Latina: la necesidad de los intelectuales militantes de 
recuperar la experiencia histórica de lucha revolucionaria desde la perspectiva de los sectores populares y de batallar por la puesta en circulación de una valoración contestataria del pasado.

La emergencia del gesto de construcción de una memoria social en la escritura de Walsh se inscribe en lo que varios autores han señalado como la respuesta ante la violencia (Link; Pesce). En Operación masacre el escritor, "asaltado por la violencia, se siente obligado a iniciar una investigación memorable, una vez más, detrás de la verdad» (Link, 57-58). Pues hay una historia que ha sido silenciada y arrojada al olvido, hay crímenes que deben ser denunciados y develados los mecanismos represivos del régimen. Por ello, en el prólogo a la cuarta edición de esa obra, de 1972, cuando Walsh se refiere al lugar de los fusilamientos, aparece la siguiente frase: «No es el menor de esos espejismos la idea de que un lugar así no puede estar tan tranquilo, tan silencioso y olvidado bajo el sol que se va a poner, sin que nadie vigile la historia prisionera en la basura cortada por la falsa marea de metales muertos que brillan reflexivamente» (Operación Masacre, 21).

En la constelación de textos a la que nos hemos referido, la respuesta a la violencia extiende sus alcances, la denuncia y esclarecimiento de los hechos que constituyen al género testimonial buscan reunir los relatos fragmentarios de las luchas populares para que la experiencia colectiva no se pierda, las lecciones no se olviden y la historia, su conocimiento y (re)escritura no sean propiedad de los dueños de todas las cosas. Hay un objetivo, como lo explica en una entrevista su última compañera, Lilia Ferreyra, que motiva esos textos: «denunciar no sólo la represión del poder o la política económica, sino todas las otras manifestaciones ideológicas del régimen militar» (195). Es decir, existe una voluntad de dar la batalla ideológica en varios planos, no sólo ofreciendo espacio de enunciación a las voces silenciadas para que salgan a la superficie con sus valoraciones opuestas a las dominantes, a fin de instaurar una dialéctica confrontativa, polifónica ${ }^{4}$, sino también configurando estos textos como un dispositivo discursivo ${ }^{5}$ de réplica ante

$4 \quad \mathrm{Al}$ respecto, las conceptualizaciones bajtinianas proponen que la cultura y el lenguaje constituyen un campo de fuerzas, por lo tanto, la comunicación entre cultura dominante y cultura dominada se da en términos de combate por la apropiación de los significados, el proceso de significación. A causa de la intersección de intereses sociales orientados en distinto sentido dentro de la misma comunidad de signos, el significado del signo es acuñado socialmente en el marco del conflicto social, lo que produce que en él convivan en conflicto valoraciones hegemónicas y subalternas. De este modo, cada signo se convierte en una «arena» de combate, en un espacio multiacentual en el que la clase dirigente, en su necesidad de mantener un orden establecido y una ideología hegemónica, se esfuerza por impartir al signo ideológico un carácter supraclasista, por extinguir u ocultar el conflicto y la lucha entre los juicios sociales de valor que aparecen en aquél, otorgándole un carácter uniacentual. En los momentos de crisis sociales o cambios revolucionarios, cuando el combate entre sectores de la sociedad se encuentra en un punto álgido, los sentidos silenciados salen a la superficie, en pugna por apropiarse del signo, con valoraciones opuestas a los acentos hegemónicos. Ese proceso permite la existencia en el espacio público de nuevas voces, de otros discursos articulados ideológicamente de modo diverso, que dan lugar a una réplica orientada a la palabra hegemónica. Así se genera en los discursos de circulación social un diálogo divergente y confrontativo que se presenta como polifónico.

5 Tomamos la noción de dispositivo discursivo de Michel Foucault, tal como la define en la entrevista publicada en la revista Ornicar: «Lo que trato de situar bajo ese nombre es, en primer lugar, un conjunto decididamente heterogéneo, que comprende discursos, instituciones, instalaciones arquitectónicas, decisiones reglamentarias, leyes, medidas administrativas, enunciados científicos, proposiciones filosóficas, morales, filantrópicas; en resumen: los elementos del dispositivo pertenecen tanto a lo dicho como a lo no dicho. El dispositivo es la red que puede establecerse entre estos elementos. En segundo lugar, lo que querría situar en el dispositivo es precisamente la naturaleza del vínculo que puede existir entre estos elementos heterogéneos. Así pues, ese discurso puede aparecer bien como programa de una institución, bien por el contrario como un elemento que permite justificar y ocultar una práctica, darle acceso a un campo nuevo de racionalidad. Resumiendo, entre esos elementos, discursivos o no, existe como un juego, de los 
la violencia doblemente orientado, hacia la palabra oficial para desmentirla y hacia los sectores populares para hilvanar las huellas de la memoria de sus luchas.

La idea de la fragmentación de la memoria de las clases oprimidas y la necesidad de contar con una narrativa que dé cuenta de su experiencia histórica es posible de ser analizada desde los aportes de Gramsci y Benjamin, lo cual permite profundizar ciertas observaciones acerca de sus implicancias, en relación con las modulaciones que el género testimonial adquiere en el programa estético-político de Walsh. Desde la perspectiva gramsciana, se advierte que las huellas de la historia de los sectores subalternos son borradas, es decir, la articulación del relato de su experiencia del pasado sufre constantes disrupciones y silenciamientos, puesto que, en general, no quedan registros de ellas. Así esos rastros quedan invisibilizados, ocultos tras la historia hegemónica, como consecuencia de la dinámica que adquiere el conflicto social en cada momento histórico específico (Gramsci, 490).

Walsh, como producto de una praxis de enfrentamiento a la violencia del régimen, lanza hacia el espacio público estos textos testimoniales donde se realiza una recuperación de la memoria colectiva, en la cual es posible urdir puntos de contacto en el lugar que dejan los extravíos generadores de discontinuidad en el conflicto social, en la resistencia popular, en la lucha revolucionaria. Se establece así una dialéctica entre pasado y presente, a partir de la cual la articulación de la experiencia histórica permite que el recuerdo nutra y movilice el proceso de constitución de sujetos políticos colectivos, legitimando posiciones y acciones contrahegemónicas. Cuando Walsh dice, hacia el final de la "Carta abierta de un escritor a la Junta Militar», que «aun si mataran al último guerrillero, no haría más que empezar bajo nuevas formas, porque las causas que hace más de veinte años mueven la resistencia del pueblo argentino no estarán desaparecidas sino agravadas por el recuerdo del estrago causado y la revelación de las atrocidades cometidas» (253), otorga al recuerdo que se recupera y que se hilvana en la urdimbre de la memoria colectiva la función de proporcionar una cohesión y una identidad para un grupo social. Una cadena de recuerdos, en tanto muestra las huellas del pasado truncado y articula una narración en el lugar de la ausencia y del extravío, concede al relato de la memoria un sentido dinámico: la memoria se manifiesta en el presente, porque estructura las nuevas experiencias apoyándose en el pasado.

Sin dudas, Walter Benjamin supo comprender los vínculos entre memoria y política, entre pasado y presente. Su conceptualización sobre la experiencia histórica provee herramientas para comprender la amalgama entre «rememoración» y "acción redentora», esto es, la importancia de la inscripción de los sujetos en un cierto pasado en el proceso de transformación de la realidad histórico-social: «Tiempo-ahora». El pasado es un botín político para cualquier acción que reivindique una incidencia dentro de la historia, por lo tanto la apropiación del pasado, o en palabras de Benjamin «la cita del pasado» (Para una crítica de la violencia, 104), puede entrañar una experiencia histórica si el contacto vivo de ambos tiempos es dialéctico, es decir, si se busca una actualización del pasado en

cambios de posición, de las modificaciones de funciones que pueden, éstas también, ser muy diferentes. En tercer lugar, por dispositivo entiendo una especie - digamos- de formación que, en un momento histórico dado, tuvo como función mayor la de responder a una urgencia. El dispositivo tiene pues una posición estratégica dominante [...]. El dispositivo se halla pues siempre inscrito en un juego de poder, pero también siempre ligado a uno de los bordes del saber, que nacen de él pero, asimismo, lo condicionan. El dispositivo es esto: unas estrategias de relaciones de fuerzas soportando unos tipos de saber, y soportadas por ellos» («El juego de Michel Foucault»). 
términos de práctica revolucionaria o transformadora del presente. El trabajo de quien usa la razón crítica, del narrador o historiador, se realiza sobre ruinas, sobre fragmentos del pasado marcados por la dominación, los conflictos, las fisuras, las rupturas, a los cuales se debe rescatar en la experiencia histórica. Es precisamente la labor del narrador, de quien articula pasado y presente, salvar a los muertos del enemigo, que cuando vence (y aún no ha cesado de vencer) se apropia de la tradición de los oprimidos y convierte el recuerdo en instrumento de la clase dominante. Para ello es necesario peinar la historia a contrapelo, ver el pasado iluminado por el presente y descubrir su promesa de futuro (111).

En ese sentido, Walsh trabaja como el narrador de Benjamin. Para el filósofo alemán, el que narra la historia, el cronista, encadena acontecimientos y los inscribe en el curso de una tradición. Su herramienta es la memoria, que le permite apropiarse de esa tradición en la medida en que el recuerdo enlaza historias dispersas fundando la cadena que la articula. De ese modo, el narrador incorpora en su relato la experiencia propia y la ajena, es una suerte de depositario del caudal moral y cultural de su pueblo que al hacerse eco de su tradición se erige en un luchador contra la mentira y el olvido, y por ello su narración es un acto de justicia, o, en palabras de Benjamin, el narrador es la figura en la que el justo se encuentra consigo mismo (El narrador). Subyace en la afirmación final la idea de que hay una narración necesaria, hay historias que deben ser contadas, recordadas, actualizadas; y en el acto de componer esas historias, la práctica de construir relatos y la de hacer justicia se encuentran.

A la luz de tales conceptualizaciones benjaminianas, Walsh se configura como un narrador, pues rescata la trayectoria de los muertos por las causas populares, reconstruye las luchas en las que participaron y repone los eslabones de la cadena de sus recuerdos. Walsh escribe esos textos iluminando los fragmentos del pasado oscurecidos por la historia oficial, para restituir a los sectores obreros y populares una tradición de rebelión, un relato de la memoria colectiva contrahegemónica: Guevara y Masetti; los jóvenes guerrilleros y los intelectuales combatientes; los obreros, los estudiantes, el pueblo luchando en las calles, enfrentando y resistiendo a las dictaduras. Así, sus textos se comportan como dispositivos discursivos que permiten reconocer la historicidad de la experiencia histórica, y en esa operación de encuentro dialéctico entre pasado y presente se instaura una posibilidad de apropiación de un pasado que peligra, pero que también revitaliza el ahora: «Esta vez es posible que se quiebre el círculo» (Walsh, «Cordobazo»).

Ahora bien: ¿en qué medida esas prácticas escriturales violentan la noción burguesa de literatura? El estudio de los textos de Walsh, donde aparece el gesto de reconstrucción de una memoria colectiva, posibilita pensar en una resignificación y extensión de los límites de la función elocutiva y perlocutiva de la escritura testimonial. Frente a la violencia represiva, esos textos testimoniales urgentes no sólo desmienten y denuncian los actos criminales del poder dominante, sino que también articulan una narrativa de la experiencia histórica de los oprimidos. Así, funcionan como una máquina textual que opera hacia el interior de lo literario, expandiendo y diversificando los efectos de lo testimonial, y en esa acción de escritura otorgan a la literatura el estatuto de herramienta, de arma con potencialidad transformadora. Esa modulación que sufre el género testimonial es también parte de un proceso de politización del arte, de su inscripción en una experiencia histórica en la cual la escritura literaria se constituye en diálogo con la práctica política del autor, es decir, como producto de la experiencia de la lucha de clases. En este 
punto continuamos reconociendo lo que lo distancia respecto del arte burgués, el arte como praxis.

\section{POLITIZACIÓN DEL ARTE: LA RESPUESTA DE UN ARTE PELIGROSO}

Cuando caracterizamos los textos de Walsh como máquinas, o bien como armas, estamos apropiándonos de una metáfora de la literatura de los setenta y del propio Walsh, utilizada muy a menudo para presentar a la escritura literaria como praxis, es decir, como una actividad que, en tanto producto histórico-cultural, es constitutiva de la realidad social. Un discurso cuya producción tiene consecuencias sobre las relaciones sociales y sus transformaciones históricas y, en esa línea, sobre las convenciones y los alcances de la concepción del discurso literario mismo. Se trata de textos que se proponen «hacer creer, hacer decir, hacer hacer» y por ello se comportan como «máquinas de producir efectos» constituyendo «acciones de escritura» (Chartier). La práctica discursiva que encarnan los textos de Walsh supone pensar en dos planos de «funcionamiento». En primer lugar, sus escritos «funcionan» en el sentido de que son máquinas de producir efectos políticos y estético-políticos, en este caso, hilvanan dialécticamente pasado y presente, contribuyen a articular una narrativa de la experiencia histórica de los oprimidos, señalan aliados y enemigos en el desarrollo del conflicto y de las luchas sociales (advierte su violencia) y operan expandiendo las fronteras de lo testimonial y por lo tanto de la literatura misma. En segundo lugar, «funcionan» desde sus estrategias de escritura, lo cual equivale a decir que dichas estrategias configuran un dispositivo discursivo que posibilita los efectos mencionados.

\section{SOBRE EL MONTAJE: EL ARTE COMO ACTIVIDAD}

Hasta ahora nos hemos ocupado de analizar uno de los aspectos del mecanismo que conforma dicho dispositivo: la producción de un núcleo de sentido, constituido por la relación entre la práctica política, la escritura testimonial y la memoria social. A partir de esa amalgama opera la recuperación a contrapelo de la experiencia histórica, de una reescritura desde la perspectiva de los sectores populares, de su lucha revolucionaria, que incluye la disputa por una valoración contestataria del pasado.

El otro aspecto está constituido por la puesta al descubierto del proceso de producción de las narraciones, es decir, de la escritura como actividad (o de la actividad de la escritura). En efecto, los textos transparentan los materiales a partir de los que se construye el relato, así como también ponen en evidencia la técnica de organización del relato mismo: el montaje. En la lectura los textos «dejan ver» que esas narraciones han sido construidas a partir de la compaginación, de la organización, del montaje de materiales diversos y provenientes de distintos registros: se entrelazan en un juego de narrativización los datos y descripciones sobre los protagonistas, la reconstrucción de diálogos, los recuerdos del narrador, declaraciones de testigos, crónicas de acontecimientos, comunicados en la prensa, datos cuantitativos económicos y sobre la represión, citas de documentos revisa- 
dos por el narrador y citas de sus lecturas. Como ejemplos de dicho modo de organizar el relato - a partir de registros diferentes montados en función de la reconstrucción de una versión de los hechos-, podemos observar los siguientes fragmentos de "Carta a Vicky», «Carta a mis amigos», «Guevara» y "Carta abierta de un escritor a la Junta Militar»:

La noticia de tu muerte me llegó hoy a las tres de la tarde. Estábamos en reunión... cuando empezaron a transmitir el comunicado. Escuché tu nombre, mal pronunciado, y tardé un segundo en asimilarlo [...]

Me quisiste, te quise. El día que te mataron cumpliste 26 años. Los últimos fueron muy duros para vos. Me gustaría verte sonreír una vez más. No podré despedirme, vos sabés por qué («Carta a Vicki», 266).

Hoy se cumplen tres meses de la muerte de mi hija, María Victoria, después de un combate con las fuerzas del Ejército. [...]

El comunicado del Ejército que publicaron los diarios no difiere demasiado, en esta oportunidad, de los hechos. Efectivamente, Vicki era Oficial $2^{\circ}$ de la Organización Montoneros, responsable de la Prensa Sindical, y su nombre de guerra era Hilda. Efectivamente estaba reunida ese día con cuatro miembros de la Secretaría Política que combatieron y murieron con ella $[\ldots]$

A las siete del 29 la despertaron los altavoces del Ejército, los primeros tiros. Siguiendo el plan de defensa acordado, subió a la terraza con el secretario político Molina, mientras Coronel, Salame y Beltrán respondían al fuego desde la planta baja. He visto la escena con sus ojos: la terraza sobre las casas bajas, el cielo amaneciendo, y el cerco. El cerco de 150 hombres, los FAP emplazados, el tanque. Me ha llegado el testimonio de uno de esos hombres, un conscripto: «El combate duró más de una hora y media. Un hombre y una muchacha tiraban desde arriba, nos llamó la atención porque cada vez que tiraban una ráfaga y nosotros nos zambullíamos, ella se reía» («Carta a mis amigos», 267).

¿Por quién doblan las campanas? Doblan por nosotros. Me resulta imposible pensar en Guevara, desde esta lúgubre primavera de Buenos Aires, sin pensar en Hemingway, en Camilo, en Masetti, en Fabricio Ojeda, en toda esa maravillosa gente que era La Habana o pasaba por La Habana en el 59 y el $60[\ldots]$

Muchos tuvieron más suerte que yo, conversaron largamente con Guevara. Aunque no era imposible, ni siquiera difícil, yo me limite a escucharlo, dos o tres veces, cuando hablaba con Masetti. Había preguntas por hacer pero no daban ganas de interrumpir o quizá las preguntas quedaban contestadas antes de que uno las hiciera [...]

Que yo recuerde, ningún jefe de ejército, ningún general, ningún héroe se ha descrito a sí mismo huyendo en dos oportunidades. Del combate de Bueycito, donde se le trabó la ametralladora frente a un soldado enemigo que lo tiroteaba desde cerca, dice: «mi participación en aquel combate fue escasa y nada heroica, pues los pocos tiros los enfrenté con la parte posterior del cuerpo» («Guevara», 283).

Quince mil desaparecidos, diez mil presos, cuatro mil muertos, decenas de miles de desterrados son la cifra desnuda de ese terror. [...]

Más de siete mil recursos de hábeas corpus han sido contestados negativamente este último año. En otros miles de casos de desaparición el recurso ni siquiera se ha presentado porque se conoce de antemano su inutilidad o porque no se encuentra abogado que ose presentarlo después que los cincuenta o sesenta que lo hacían fueron a su turno secuestrados.

Veinticinco cuerpos mutilados afloraron entre marzo y octubre de 1976 en las costas uruguayas, pequeña parte quizás del cargamento de torturados hasta la muerte en la Escuela 
de Mecánica de la Armada, fondeados en el Río de la Plata por buques de esa fuerza, incluyendo el chico de 15 años, Floreal Avellaneda, atado de pies y manos, «con lastimaduras en la región anal y fracturas visibles» según su autopsia.

Un verdadero cementerio lacustre descubrió en agosto de 1976 un vecino que buceaba en el Lago San Roque de Córdoba, acudió a la comisaría donde no le recibieron la denuncia y escribió a los diarios que no la publicaron [...]

Tampoco en las metas abstractas de la economía, a las que suelen llamar «el país», han sido ustedes más afortunados. Un descenso del producto bruto que orilla el $3 \%$, una deuda exterior que alcanza a 600 dólares por habitante, una inflación anual del $400 \%$, un aumento del circulante que en solo una semana de diciembre llegó al 9\%, una baja del $13 \%$ en la inversión externa constituyen también marcas mundiales, raro fruto de la fría deliberación y la cruda inepcia («Carta abierta...», 251-252).

Los textos develan su textura, o mejor dicho, descubren su factura y por ende su carácter de construidos a partir de fragmentos discursivos cuya circulación en la sociedad es subterránea, marginal o silenciada. En la configuración del relato, los fragmentos son rescatados por el narrador e inscritos en un ensamble de voces, en un tejido que da cuerpo a una narración que resulta contestataria a las versiones dominantes de la historia y que soporta en ese cuerpo discursivo, construido a través del montaje de fragmentos, una experiencia histórica de resistencia y lucha revolucionaria.

El dispositivo de los textos provoca, desde una perspectiva benjaminiana, una movilización de la experiencia histórica de los sujetos ( La obra de arte en la época de su reproductibilidad técnica, 54). Sin embargo, ello es posibilitado no solamente por la configuración de un núcleo de sentido que relaciona dialécticamente pasado y presente en el vínculo entre memoria de los sectores populares y relato testimonial, sino también porque esa movilización de la experiencia histórica de los sujetos es expresada, desde el punto de vista formal, en la estrategia discursiva del montaje. Esa estrategia transparenta los procedimientos de producción de los propios textos, dando lugar a una estructura formal que es significante en sí misma, porque supone una toma de posición crítica con respecto a los modos de posibilitar la experiencia histórica, asumidos por la obra de arte. En esa línea, como establece Amar Sánchez, se hace necesario pensar estos textos testimoniales como políticos, pero no únicamente por su condición de "relato de denuncia», sino en el sentido benjaminiano de que encuentran su ejercicio político más significativo en el hecho de que generan, a partir de su dispositivo discursivo, un gesto de politización del discurso literario.

\section{TEXTOS URGENTES: UN ARTE DESACRALIZADO Y MOVILIZADOR DE LA EXPERIENCIA HISTÓRICA}

Walter Benjamin cierra su ensayo «La obra de arte en la época de la reproductibilidad técnica» con una conocida afirmación: la autoalienación de la humanidad «ha alcanzado un grado que le permite vivir su propia destrucción como un goce estético de primer orden. Éste es el esteticismo de la política que el fascismo propugna. El comunismo le contesta con la politización del arte» (57). Siguiendo la explicación de Eduardo Grüner sobre esas ideas benjaminianas, consideramos que la «politización del arte» no se vincula 
necesariamente con los temas explícitos de la obra (su contenido), sino que supone, como se ha mencionado, la «movilización de la experiencia histórica de los sujetos», expresada en la propia estructura formal de dicha obra, en oposición a la monumentalización estática de esa experiencia histórica, operada por el fascismo, y su «estetización de la política» («El espíritu de lo real»). En el caso de los textos de Walsh, es reconocible una politización del arte que se despliega en el dispositivo descrito, puesto que, por una parte, desde el plano del significado, realiza una recuperación de la memoria colectiva, articulando la tradición fragmentada de las luchas populares a través del encuentro dialéctico, movilizador y transformador entre pasado y presente; y, por otra parte, porque hace evidente el mecanismo de producción de los textos, al organizarlos a partir del montaje de fragmentos de discurso que se ensamblan en el relato. El montaje, en este caso, constituye una técnica que se configura como una estrategia del discurso, en tanto recupera la visibilidad de los mecanismos de producción del texto.

En tal sentido, el montaje genera varias implicancias estético-políticas en relación con lo testimonial. En primer lugar, una escritura que revela su construcción misma, expone su hechura a partir de materiales que han sido rescatados como consecuencia de búsquedas y hurgamientos, y que luego han sido enlazados para producir el relato testimonial. Los textos no son presentados como objetos acabados y puestos en circulación, sino que se manifiestan como el resultado de un proceso previo, es decir, se trata de un trabajo de producción que queda en evidencia y que está dado fundamentalmente por la manipulación y organización crítica de materiales discursivos dispersos a causa del desarrollo de la lucha entre grupos sociales. Así, esa estrategia permite reconocer que la realidad histórico-social constituye un "campo de batalla", que los fragmentos recuperados son huellas que dan cuenta de las fracturas, desgarramientos y discontinuidades que caracterizan a la historia de los vencidos, una historia «intermitente», "subterránea» y «espasmódica» (Grüner, «Lecturas culpables», 135), marcada por el conflicto entre clases y sus parciales y transitorias resoluciones. A propósito de la historia de los vencidos, Grüner plantea el siguiente razonamiento crítico:

Esa historia no es lineal ni evolutiva. [...] Solo cada tanto - por ejemplo, en los momentos de crisis de hegemonía, como diría Gramsci, o desde luego, de crisis abiertamente revolucionaria, o más generalmente de catástrofe social y cultural- esa historia emerge a la superficie, y entonces toda la historia se ve convulsionada y redefinida. Mientras tanto, permanece soterrada, transcurre «fuera de la escena», pero no por ello inmóvil y sin consecuencias: al contrario, es en su propio nivel el «determinante en última instancia» de lo que ocurre en la superficie, es el inconsciente político [...] de la imago de "progreso» de los vencedores, sobre la cual insistentemente retorna desde lo reprimido para poner en cuestión la falsa totalidad con cuya imagen se presenta la historia de los vencedores («Lecturas culpables», 136)

Por lo señalado, la estrategia escritural del montaje vehiculiza en los textos de Walsh una crítica a los modos capitalistas de construir los relatos históricos hegemónicos y hacia los propios fundamentos del arte burgués. Los relatos testimoniales walshianos constituyen un cuestionamiento y, simultáneamente, una práctica crítica orientada hacia el punto de vista de «la cultura burguesa», que se coloca frente al mundo «en una posición estática y contemplativa». Lukács, en Historia y conciencia de clase, define la "cosificación» de la conciencia como la contemplación pasiva de un mundo estático, cosificado, en la cual aparece el sujeto separado del objeto, ambos en estado de inmovilidad, lo cual 
constituye un punto de vista que se sostiene en condiciones históricas determinadas, la organización capitalista de la producción y reproducción de la vida social. En otros términos, esa posición contemplativa propia de la burguesía ignora, oculta, deja «fuera de escena» aquella dimensión que está dada por la esfera de la producción, al ignorar las mediaciones que permiten religar el proceso de producción con el objeto producido. El pensamiento cosificado se configura como una reproducción pasiva de índole simbólica de una realidad mutilada en la que lo que se desconoce es que el mundo de lo real (vale decir también la historia y el arte) es el resultado de un proceso de producción y, por lo tanto, es histórico, no eterno, es movimiento y transitoriedad y por ello puede ser transformado.

Como indica Grüner, la cultura burguesa — que será denominada más tarde por Marcuse como cultura afirmativa de lo real- supone una posición consumidora y no productora de lo real («Lecturas culpables», 119). Marcuse, en su trabajo Cultura y Sociedad, lo define de la siguiente forma:

Bajo cultura afirmativa se entiende aquella cultura que pertenece a la época burguesa y que a lo largo de su propio desarrollo ha conducido a la separación del mundo anímicoespiritual, en tanto reino independiente de los valores, de la civilización, colocando a aquél por encima de ésta. Su característica fundamental es la afirmación de un mundo valioso, obligatorio para todos, que ha de ser afirmado incondicionalmente y que es eternamente superior, esencialmente diferente del mundo real de la lucha cotidiana por la existencia, pero que todo individuo «desde su interioridad», sin modificar aquella situación fáctica, puede realizar por sí mismo (s.n.).

A este modo de cultura le corresponde el arte aurático. El «aura» de la obra de arte es, para Benjamin, una forma de la experiencia estética que se da en el contacto o en la visión de la obra original («La obra de arte»). A dicha experiencia estética la califica como la aparición irrepetible de una lejanía que le confiere a la obra un carácter inaccesible. La reproducción técnica, de alguna manera, neutraliza esa distancia infinita y acerca la obra al espectador. Con las «técnicas de reproducción» esa aura se arruina, declina, y en tal declinación se recupera la potencialidad para pensar y percibir la obra de arte como un objeto manipulable, con el cual el espectador puede tener una relación más activa, en el sentido de que ya la experiencia no queda limitada a la pura contemplación. La experiencia aurática sólo es posible frente a un objeto estético acabado, en el que se ha elidido la existencia de su proceso de producción. Frente a ese tipo de experiencia estética, el montaje constituye una técnica que tiende al arruinamiento del arte aurático, ya que pone el acento en evidenciar el mecanismo de construcción, no en el objeto construido para ser contemplado. Las técnicas utilizadas para la producción de las obras de arte son vistas por Benjamin como un cierto tipo de instrumento que se inscribe en determinadas relaciones histórico-sociales. El montaje, entonces, es una técnica contestataria inscrita en un proyecto que apunta a la superación del arte burgués y a subvertir los modos en que se produce la experiencia estética, en el marco de una cultura afirmativa. En la experiencia singular de Walsh aparece como uno de los principios constitutivos de la organización de su narrativa testimonial, asumida como una respuesta con potencialidad antiaurática o, en términos del propio escritor, «desacralizadora».

En un reportaje que Ricardo Piglia le realizara a Rodolfo Walsh en marzo de 1970, este último rechaza la condición inofensiva y sacralizada del arte y la literatura y le confiere a los géneros testimoniales y a las técnicas de trabajo escritural sobre lo testimonial 
«inmensas posibilidades artísticas» para superar los formatos de la literatura burguesa y para establecer un vínculo vital entre arte y política:

Yo creo que esa concepción es típicamente burguesa, ¿y por qué? Porque evidentemente la denuncia traducida al arte de la novela se vuelve inofensiva, no molesta para nada, es decir, se sacraliza como arte. [...] Creo que es poderosa [la novela], lógicamente muy poderosa, pero al mismo tiempo creo que gente más joven, que se forma en sociedades distintas, sociedades no capitalistas o bien que están en proceso de revolución, va a aceptar con más facilidad la idea de que el testimonio y la denuncia son categorías artísticas por lo menos equivalentes y merecedoras de los mismos trabajos y esfuerzos que se le dedican a la ficción. En un futuro, tal vez, inclusive se inviertan los términos: que lo que realmente se aprecie en cuanto a arte sea la elaboración del testimonio o del documento, que, como todo el mundo sabe, admite cualquier grado de perfección. Evidentemente en el montaje, la compaginación, la selección, en el trabajo de investigación, se abren inmensas posibilidades artísticas. [...] No se trata de firmar el certificado de defunción de la novela o de la ficción, pero es muy probable que se pueda caracterizar a la ficción en general como el arte literario característico de la burguesía de los siglos XIX y XX principalmente, por lo tanto no como una forma eterna e indeleble, sino como una forma que puede ser transitoria. [...] Pensar que aquí hasta hace poco tiempo hubo quien sostenía que el arte y la política no tenían nada que ver, que no podía existir un arte en función de la política, algo que formaba una vez más parte de ese juego inconsciente en la medida en que las estructuras sociales funcionan también como inconscientes; es parte de ese juego destinado a quitarle toda peligrosidad al arte, toda acción sobre la vida, toda influencia real y directa sobre la vida del momento [...] (Baschetti, 70-72).

Walsh adjudica un valor decisivo a la forma artística desde la que se trabajan determinados referentes. Aun los relatos de denuncia, cuando son articulados mediante formatos y estrategias discursivas que responden a la lógica contemplativa de la «cultura afirmativa» y a los principios cosificantes del arte burgués, pierden su peligrosidad, se sacralizan y se vuelven inofensivos. ¿Por qué piensa en el arte testimonial como portador de una peligrosidad? Los formatos y técnicas ligados a lo testimonial promueven un modo de experiencia estética que evidencia las mediaciones existentes entre los objetos culturales y su proceso de producción, lo hacen a través de la utilización del montaje y la compaginación de materiales discursivos como fundamento constructivo del relato. Así, la literatura testimonial no responde a un modo aurático de recepción, ya que propicia una práctica de interpretación activa (Grüner, «Lecturas culpables», 124) en la que, por una parte, hay conciencia del carácter de construidos de los relatos a partir de enunciados recuperados, y por otra parte, se propone como la articulación de una narrativa de la experiencia histórica de los sujetos en lucha, vinculando dialécticamente el presente y el pasado de las versiones contrahegemónicas de la historia, para construir una ligazón en términos de práctica revolucionaria o transformadora. Esa práctica implica un acto de conocer el mundo real y las construcciones simbólicas, «mediante el mismo movimiento que pugna por transformarlo» (Grüner, «Lecturas culpables», 124). En nuestro caso, los textos testimoniales de Walsh no sólo develan críticamente los modos de funcionamiento de la cultura y el sistema social burgueses, sino que también evidencian que son productos históricos surgidos del conflicto social y, por tanto, están sujetos a esta dinámica de la historia que no se detiene y que contiene la eventualidad de la desaparición de su hegemonía. 


\section{CONSIDERACIONES FINALES}

En el presente trabajo hemos propuesto analizar las modulaciones del programa estéticopolítico de Rodolfo Walsh hacia los géneros testimoniales, en el período de los sesenta y setenta. La constelación de textos abordada posee un núcleo de sentido constituido en y por la dialéctica histórica entre práctica política, escritura literaria (testimonio) y memoria social. Se trata de un conjunto de textos que muestra una disputa por la representación de la historia, por la rememoración de la experiencia pasada. Ahora bien, esa preocupación por la historia está anclada a la urgencia del presente: el «instante de peligro» que impone la represión de los sectores dominantes.

De ahí que hayamos afirmado, en continuidad con el epígrafe que abre este ensayo, el primado de la política sobre la historia (Benjamin). Es decir, si hay una disputa por el sentido del pasado, un conflicto entre diferentes representaciones, es porque la misma historia es un campo de batalla, un terreno áspero marcado por antagonismos sociales. La recuperación que opera Walsh de una memoria subterránea, la denuncia que hace de la violencia política y el conocimiento histórico que ponen en juego sus textos testimoniales se sostienen en la experiencia histórica de la lucha de clases, se apoyan en su propia práctica política y sus compromisos asumidos en el proceso de transformación del mundo.

En tanto textos urgentes, son portadores de una peligrosidad. Sus testimonios contribuyen a una reconstrucción de la memoria colectiva de los sectores subalternos y oprimidos, una lectura a contrapelo de la historia que abre la posibilidad de constituir posiciones y prácticas contrahegemónicas. Esa peligrosidad deviene del hecho de que los textos de Walsh hacen presente lo que está «fuera de escena», revelan la historicidad propia tanto del arte como de la historia, de ambos como praxis, como actividad social de los seres humanos. Dos son las dimensiones que reintroduce: por una parte, la perspectiva sobre la que reconstruye la experiencia pasada (la recuperación de los pasados truncados y la violencia que los abortó), «dejar ver» cómo se hace la historia — la lucha de clases-; por la otra, cómo se escribe (el proceso de producción literaria, el montaje).

En esa reposición de lo que no es inmediatamente percibido, los textos testimoniales aparecen como una práctica crítica que revela la «incompletud», el «inacabamiento», el carácter de construcción histórica de la literatura, del mundo real y de la historia. Dado que son mostrados en tanto producto de un trabajo y en tanto proceso de producción, dan cuenta de la existencia de una dimensión invisibilizada, oculta, que debe ser recuperada, no sólo porque explica el todo, sino porque pone en juego la presencia del conflicto, introduce la posibilidad de hacer consciente la existencia de un modo de producir y, por lo tanto, abre el camino para la intervención sobre lo producido inacabado. En otras palabras, incorpora la potencialidad de la transformación, de la «apertura de la historia» (Löwy, 169-185).

Ahora bien, esa reorganización de los marcos de visibilidad que pone en juego el programa estético-político de Walsh (testimoniar la violencia política) no refiere a un problema de "contemplación» (una mejor interpretación del mundo y de los sucesos históri$\cos )$, sino a una práctica política. Aquí es necesario señalar la profunda amalgama entre experiencia estética y experiencia histórica sobre la que se configura esa peligrosidad de su literatura, esa capacidad para cuestionar la modalidad del arte burgués, la visión de la historia desde los sectores dominantes y el propio orden social capitalista, mostrando 
su transitoriedad y las condiciones de posibilidad de su transformación. En ese sentido, los relatos testimoniales de Walsh constituyen un modo de conocimiento profundamente crítico operado desde la literatura. Dicho modo de conocer está basado en la praxis que supone una actividad política transformadora y, por lo tanto, generadora de una concepción del mundo que se estructura en torno a la existencia de conflictos sociales e ideológicos no resueltos, que tienen un desarrollo histórico inacabado.

Es por ello que el dispositivo discursivo que funciona en estos textos da lugar a una movilización de la experiencia histórica de sectores populares y fuerzas contrahegemónicas que, a la vez que imposibilita la fosilización o monumentalización del pasado (al recuperar los pasados truncados), visibiliza la violencia inscrita en el presente. De ese modo, favorece una experiencia estética que se aparta de la contemplación inmóvil para ir en la búsqueda de una conciencia activa y crítica de la condición simbólica e histórica propia de las obras de arte. En esta analogía entre experiencia histórica y estética, el dispositivo desplegado en los textos de Walsh configura un vínculo entre práctica política y conocimiento histórico - y la práctica literaria como mediación-, que se reconoce en la respuesta que una fuerza social transformadora puede generar para la crisis de la cultura burguesa: la politización del arte.

\section{REFERENCIAS}

Amar Sánchez, Ana María. El relato de los hechos. Rodolfo Walsh: testimonio y escritura. Rosario: Beatriz Viterbo, 1992. Medio impreso.

Bajtin, Mijail. Teoría y estética de la novela. Madrid: Taurus, 1989. Medio impreso.

Balvé, Beba y otros. Lucha de calles, lucha de clases: elementos para su análisis, Córdoba 1971-1969. Buenos Aires: Ediciones Ryr, 2005. Medio impreso.

Baschetti, Roberto. Rodolfo Walsh, vivo. Buenos Aires: Ediciones De la Flor, 1994. Medio impreso.

Benjamin, Walter. Para una crítica de la violencia. México: La nave de los locos - Premiá editora, 1982. Medio impreso.

_. «La obra de arte en la época de su reproductibilidad técnica». Discursos Interrumpidos I. Madrid: Taurus, 1987. 16-57. Medio impreso.

___. El narrador. Madrid: Editorial Taurus, 1991. Medio impreso.

Catanzaro, Gisela. "¿Por qué la Historia y no más bien la nada? Notas sobre el problema del tiempo y la causalidad». Las aventuras del marxismo. Ed. Grisela Catanzaro y Ezequiel Ipar. Buenos Aires: Gorla, 2003. 17-104. Medio impreso.

Chartier, Roger. El juego de las reglas: lecturas. México: Fondo de Cultura Económica, 2000. Medio impreso.

Dalmaroni, Miguel. La palabra justa. Literatura, crítica y memoria en Argentina (19602002). Santiago: Melusina / RIL editores, 2004. Medio impreso.

Ferreyra, Lilia. «Rigor e inteligencia en la vida de Rodolfo Walsh». Rodolfo Walsh, vivo. Ed. Roberto Baschetti. Buenos Aires: Ediciones De la Flor, 1994. 241-253. Medio impreso.

Foucault, Michel. «El juego de Michel Foucault». Con-Versiones, 2006. Sitio Web. Fecha de ingreso: 6 de agosto de 2009. 
Gramsci, Antonio. Antología. Buenos Aires: Siglo XXI, 2004. Medio impreso.

Grüner, Eduardo. «Lecturas culpables. Marx(ismos) y la praxis del conocimiento". La teoría marxista hoy. Problemas y perspectivas. Atilio Borón (comp.). Buenos Aires: CLACSO, 2006. 105-148. Medio impreso. . «El espíritu de lo real». Revista Conjetural 47 (2007), 43-55. Medio impreso.

Halbwachs, Maurice. Los marcos sociales de la memoria. Barcelona: Anthropos, 2004. Medio impreso.

Jelin, Elizabeth. Los trabajos de la memoria. Madrid: Siglo XXI, 2002. Medio impreso.

Link, Daniel. La chancha con cadenas. Doce ensayos de literatura argentina. Buenos Aires: Ediciones del Eclipse, 1994. Medio impreso.

Löwy, Michael. Walter Benjamin. Aviso de incendio. Buenos Aires: Fondo de Cultura Económica, 2005. Medio impreso.

Lukács, Georg. Historia y conciencia de clase. México: Grijalbo, 1969. Medio impreso. Marcuse, Herbet. Cultura y Sociedad. Buenos Aires: Editorial Sur, 1968. Medio impreso.

Pesce, Víctor. «Rodolfo Jorge Walsh, el problemático ejercicio del relato». Textos de y sobre Rodolfo Walsh. Ed. Jorge Lafforgue. Buenos Aires / Madrid: Alianza, 2000. 39-60. Medio impreso.

Ricoeur, Paul. La Mémoire, l’histoire, l'oubli. París: Éditions du Seuil, 2000. Medio impreso.

Voloshinov, Valentín. El marxismo y la filosofía del lenguaje. Madrid: Alianza Editora, 1992. Medio impreso.

Walsh, Rodolfo. Operación Masacre. Buenos Aires: Ediciones de la Flor, 2003. Medio impreso.

. "Carta abierta de un escritor a la Junta Militar». Rodolfo Walsh, vivo. Ed. Roberto

Baschetti. Buenos Aires: Ediciones de la Flor, 1994. 241-253. Medio impreso.

. "Cordobazo". Periódico de la CGT de los Argentinos, sin fecha. Medio impreso.

___. Ese hombre y otros papeles personales. Buenos Aires: Ediciones de la Flor, 2007. Medio impreso. . "Carta a Vicky". Ese hombre y otros papeles personales. Buenos Aires: Ediciones de la Flor, 2007. 265-266. Medio impreso.

. "Carta a mis amigos". Ese hombre y otros papeles personales. Buenos Aires: Ediciones de la Flor, 2007. 267-270. Medio impreso.

. «Diciembre 29» [sobre la muerte de Francisco Urondo]. Ese hombre y otros papeles personales. Buenos Aires: Ediciones de la Flor, 2007. 271-273. Medio impreso.

_-_. "Guevara». El violento oficio de escribir. Obra periodística 1953-1977. Buenos Aires: Ediciones de la Flor, 2008. 283-288. Medio impreso.

. "Prólogo a Los que luchan y los que lloran de Jorge Masetti». Rodolfo Walsh, vivo.

Ed. Roberto Baschetti. Buenos Aires: Ediciones de la Flor, 1994. 272-282. Medio impreso.

Williams, Raymond. Marxismo y literatura. Barcelona: Península, 2002. Medio impreso.

Recepción: 25 de abril de 2011

Aceptación: 10 de mayo de 2011 